\section{Vol. 38, Issue 3, June 2011}

Review Article

173 Adoptive Immunotherapy after Allogeneic Hematopoietic Progenitor Cell Transplantation: New Perspectives for Transfusion Medicine Hofmann, S.; Greiner, J. (Ulm)

\section{Original Articles}

183 Influence of Gestational Age, Cesarean Section, and Hematocrit on Interleukin-8 Concentrations in Plasma and Detergent-Lysed Whole Blood of Non-Infected Newborns

Neunhoeffer, F.; Lipponer, D.; Eichner, M.; Poets, C.F.;

Wacker, A. (Tübingen); Orlikowsky, T. (Aachen)

190 Iron Balance in Regular Blood Donors Mozaheb, Z.; Khayami, M.; Sayadpoor, D. (Mashhad)

195 Platelet Recruitment during Multiple Donor Platelet Apheresis Differs between Cell Separators Fontana, S.; Keller, P.; Mansouri Taleghani, B. (Bern)

\section{Clinical Information}

199 Report on Notifications Pursuant to \$21 German Transfusion Act for 2008 and 2009

Henseler, O.; Heiden, M.; Haschberger, B.; Hesse, J.; Seitz, R. (Langen)

\section{Obituary}

217 Obituary Univ.-Prof. Dr. med. Hans Bergmann Gabriel, C.; Blauhut, B. (Linz)

219 News / Ticker

221 Meetings and Conferences

224 Guidelines for Authors

182 Imprint

\section{Band 38, Heft 3, Juni 2011}

\section{Übersichtsarbeit}

173 Adoptive Immuntherapie nach allogener Blutstammzelltransplantation: Neue Perspektiven in der Transfusionsmedizin Hofmann, S.; Greiner, J. (Ulm)

\section{Originalarbeiten}

183 Einfluss von Gestationsalter, Kaiserschnitt und Hämatokrit auf die Interleukin-8-Konzentration im Plasma und Detergenz-lysiertes Vollblut von nichtinfizierten Neugeborenen

Neunhoeffer, F.; Lipponer, D.; Eichner, M.; Poets, C.F.;

Wacker, A. (Tübingen); Orlikowsky, T. (Aachen)

190 Eisenbalance bei regulären Blutspendern Mozaheb, Z.; Khayami, M.; Sayadpoor, D. (Mashhad)

195 Die Rekrutierung von Plättchen während der multiplen Thrombozytapherese unterscheidet sich zwischen Zellseparatoren

Fontana, S.; Keller, P.; Mansouri Taleghani, B. (Bern)

\section{Klinische Information}

199 Bericht zur Meldung nach §21 Transfusionsgesetz für die Jahre 2008 und 2009

Henseler, O.; Heiden, M.; Haschberger, B.; Hesse, J.; Seitz, R. (Langen)

\section{Obituary}

217 Nachruf Univ.-Prof. Dr. med. Hans Bergmann Gabriel, C.; Blauhut, B. (Linz)

219 News / Ticker

221 Tagungen und Kongresse

224 Hinweise für Autoren

182 Impressum

\section{KARGER}

Fax +497614520714

Information@Karger.de

www.karger.com 